\title{
Estrategias Para Tranformar la Ciudad: Caracas Del Valle al Mar, guía de arquitectura y paisaje.
}

\author{
IVAN GONZALEZ VISO \\ Facultad de Arquitectura y Urbanismo, Universidad Central de Venezuela
}

En una ciudad compleja como Caracas, sometida a grandes fuerzas y acelerados cambios, pareciera útil e imperativo determinar desde múltiples perspectivas, cuales han sido los aportes de la arquitectura a la ciudad. Una guía es un modo de tener una visión completa y sinóptica, de traer a presencia la imagen de la capital a través de sus edificaciones y espacios públicos. Este ensayo plantea que una guía de arquitectura, puede ser una valiosa herramienta para conocer la ciudad y a partir de allí, poder proponer tácticas urbanas que permitan su transformación.

\section{CARACAS PERDIDA.}

En 1953, el fotoperiodista de origen húngaro Cornell Cappa (19082008), quien viajaba por primera vez a Venezuela y a América Latina, fue asignado por la prestigiosa revista LIFE para realizar un reportaje sobre Caracas. Las descriptivas imágenes captadas por el lente de $\mathrm{Cappa}^{1}$, revelaban la vida urbana de una ciudad en proceso de modernización: grandes obras de vialidad, autos último modelo, edificaciones modernas y sorprendentes, una agitada vida nocturna, grandes demoliciones que daban paso a nuevas obras de infraestructura, nuevas plantas industriales, y el inicio del Campeonato Mundial de Baseball amateur. Una ciudad que se debatía entre anclarse a su pasado mas reciente o emprender el salto a la modernidad. Trece años más tarde la revista LIFE volvería a publicar en su versión en español en 1966 una gran sección especial sobre Venezuela titulada "La vibrante Venezuela con un portafolio de colores", pero esta vez con imágenes de la capital y del país registradas por el fotógrafo y cineasta venezolano de origen húngaro Joseph Fabry², que reflejaban la consolidación de una ciudad moderna. Tanto las imágenes de Cornell como las de Fabry lograron captar con una distancia de poco mas de una década, el inicio y la consolidación del modelo de ciudad moderna, inmersa en un profundos cambios y grandes transformaciones que permitieron que la capital cambiara de escala, fruto de una colaboración interdisciplinar, una apertura hacia "lo nuevo", y una alta renta petrolera; una corriente que permeó por muchos años la cultura de la capital y la marcó con una impronta que hoy aún permanece.
La escala, complejidad y audacia de proyectos como el Centro Simón Bolívar de Cipriano Domínguez (1954), o el ultramoderno sistema teleférico que conducía al Hotel Humboldt (1956) situado en el tope del Ávila a 2.140 metros del altura (snm)., apostaron por las posibilidades que ofrecía la arquitectura moderna dentro de un portentoso marco geográfico, con una estética que emergía como un modelo de desarrollo que se extendía en América Latina.

La modernización incluyó un ambicioso plan vial desarrollado a partir de 1951, con vías de comunicación expresas que permitieron acercar a la capital al litoral, a través de la autopista más cara del mundo, cuyo valor fue de $\$ 3.500 .000$ por kilómetro, tal y como fué reseñado en la revista Popular Mechanics en 1951. El automóvil transformó la ciudad, y paso a ser protagonista, reflejando el American way of life, que privilegió las vías rápidas al interior de la ciudad, siguiendo las directrices del planificador norteamericano Robert Moses, quién participó como asesor en la planificación del plan vial de Caracas en 1948. Caracas se convirtió en un territorio de experimentación donde se aplicaron las ideas del movimiento moderno surgido en Europa. Allí se generaron condiciones "que la arquitectura europea hubiera deseado para sí desde todo punto de vista, desde la liberación del peso de la historia, la ausencia de resistencia institucional... La modernidad desenfadada que caracterizó los años cincuenta en toda Latinoamérica fue motivo de sorpresa y admiración en el resto el mundo"3

La arquitectura venezolana irrumpe así en forma contundente en la escena internacional en la década de los cincuenta, en un momento en que los arquitectos, las instituciones y las publicaciones de todo el mundo miraban con atención el fenómeno en América Latina. "Las razones que explican este hecho se sustentaban, entre muchas otras, en el acelerado desarrollo económico del cual la arquitectura pasó a ser manifestación física, y en que la región venía disfrutando de un período fructífero en términos de su producción arquitectónica desde la década anterior, al no verse afectada por la Segunda Guerra Mundial"4. Ese proceso de modernización se tradujo en nuevos modelos de vivienda unifamiliar moderna, nuevas tipologías edificatorias para centros comerciales, edificios de oficinas para sedes petroleras y urbanizaciones suburbanas bajo criterios de ciudad jardín, planificadas por grandes arquitectos y planificadores extranjeros 5 . A ello se sumo la 


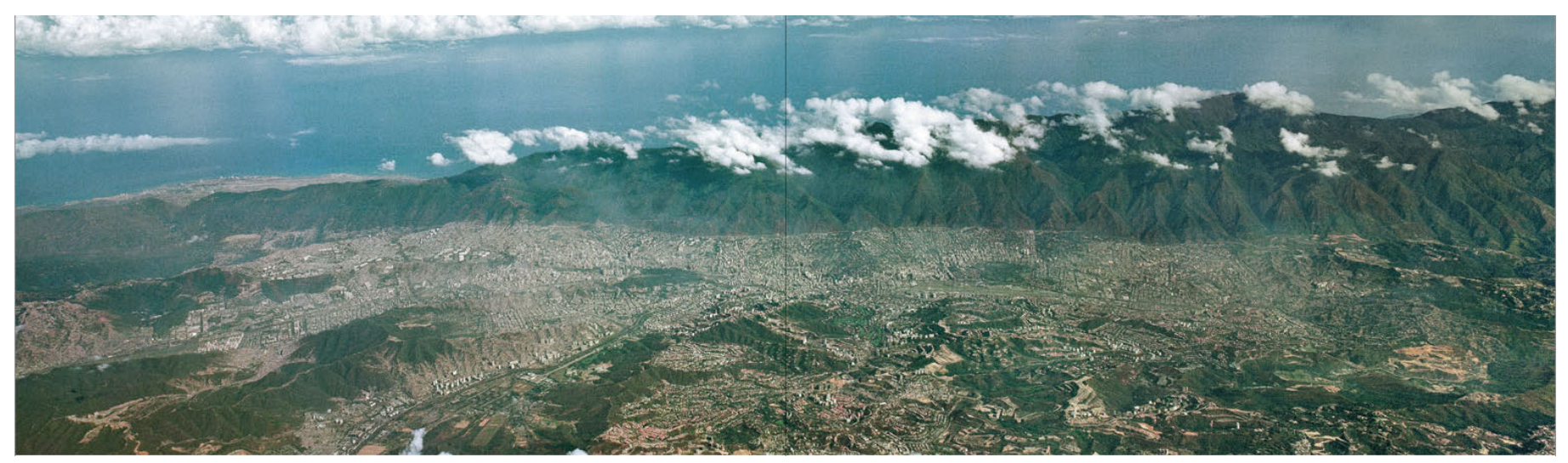

Figura 1: Vista aérea, la ciudad, la montaña y el mar. Charles Brewer Carías.

emigración de mano de obra europea calificada a América Latina como consecuencia de la guerra, que contribuyó al desarrollo tecnológico de la construcción y avance de la profesión.

A partir de la década de los cuarenta la nueva arquitectura moderna adquirió una dimensión heroica y simbólica transformándose en una clara señal de progreso. La materialización de una modernidad súbita se convirtió en una evidencia irrefutable de un proceso de modernización que transformó al país estructuralmente. Las respuestas de la arquitectura a la geografía y al clima, se tradujeron en un nítidas soluciones espaciales e interpretaciones locales de las ideas del movimiento moderno, originando que la percepción de Venezuela en las publicaciones especializadas de arquitectura del exterior cobrara mucha atención en el período comprendido entre 1950 y $1960^{6}$.

Sin embargo Caracas, la ciudad heroica en su proyecto de modernidad, en las últimas dos décadas se ha desplazado a los últimos lugares en el ranking de las ciudades de la región. Caracas no cree en nadie, ni nadie cree en Caracas. La capital que una vez estuvo volcada al futuro y fue un emblema sudamericano en los años 50 , gracias a la renta petrolera, hoy se encuentra fuera del panorama latinoamericano y mundial, señalada como una urbe caótica, maltratada, insegura y rezagada en la construcción de proyectos urbanos innovadores y transformadores, sin políticas públicas progresistas que promuevan interés alguno en ella. Una ciudad carente del pujante desarrollo de otras urbes latinoamericanas. "Caracas es hoy el antónimo del progreso, donde luce imposible generar riqueza urbana dentro de un régimen político que le niega a la ciudad su rol fundamental para el desarrollo. Una ciudad castigada como fundamento y principio político para su inmovilización productiva, paralizando su desarrollo con el fin de transformarla en la vituperada ciudad comunal socialista del siglo $\mathrm{XXI}^{\prime \prime}$.

Si existe una ciudad privilegiada geográficamente, que necesita desesperadamente ser comprendida, retomar su brillo y ser consciente de su belleza innata e indestructible, esa es Caracas. La presencia del Ávila es, y sigue manteniéndose como el principal elemento geográfico y paisajístico de la ciudad, hasta el punto que todas las bondades de nuestra ciudad a veces solo parecieran tener explicación por su presencia. El Ávila es un marco geográfico abrumador que es referencia permanente en los caraqueños y cuya naturaleza cambiante no deja de sorprender y corresponsable de un clima privilegiado, temperaturas agradables, vientos constantes, y un sistema autolimpiante de quebradas.

Por ello cabe preguntarse: ¿Es justo dejar que todas las virtudes y la belleza de Caracas descansen solo en su marco paisajístico, geográfico y ambiental, el Ávila, y no emprender acciones para que recupere el brillo que una vez tuvo? ¿De que forma rescatar, enaltecer, valorar el patrimonio construido, poner de relieve estrategias para su rescate, $y$ construir vínculos con sus habitantes?

\section{UNA GUIA DE ARQUITECTURA COMO HERRAMIENTA}

En un contexto complejo como Caracas, una guía de arquitectura puede resultar un instrumento útil para conocer la ciudad, y puede convertirse en una herramienta de consulta para liderar su transformación urbana. Un medio útil para recuperar la fe en la posibilidad del descubrimiento, en la posibilidad del rescate de nuestro patrimonio y de que éste nos resulte relevante y transformador. Un proyecto que movilice a sus habitantes frente a la saturación de imágenes provenientes de las redes sociales que nos ha hecho creer haberlo visto todo. Un medio capaz de guiar tanto al ciudadano que la recorre como al funcionario que la gobierna.

La guía se fundamenta en dos axiomas: observar para descubrir y conocer para actuar. Ella intenta reconstruir y narrar la ciudad a través de sus arquitecturas, pero también guiar en el conocimiento, la práctica, y la experiencia de la arquitectura examinando las principales obras de la ciudad, promoviendo una actitud curiosa ante lo que se observa, impulsando el gusto por descubrir fortaleciendo la mirada del arquitecto. Pero la construcción de una guía de arquitectura y ciudad bajo la mirada espiritualizadora del arquitecto, que es quien otorga sustancia al hecho de la forma, debe contener elementos específicos que la diferencien de una guía con fines turísticos. La mirada del arquitecto busca con vehemencia imágenes que lo sorprendan y, una vez que aparecen, trata de entender las estructuras y sistemas que las originan y sustentan, para luego armar un relato propio. A su vez, una guía invita a vestirnos con el difícil traje de ser paseantes por la ciudad, ver su mejor arquitectura y deambular por sus calles ajenos al ajetreo cotidiano. Y en ese viaje el arquitecto mira, pero mira de una forma distinta. Aquí entra en juego el concepto de sights utilizado por John Murray $\mathrm{III}^{9}$ en 1836 en sus guías de viaje, donde abre una nueva forma de conocer que se acerca mucho a la "mirada médica" propuesta por Focault. ${ }^{10}$ 


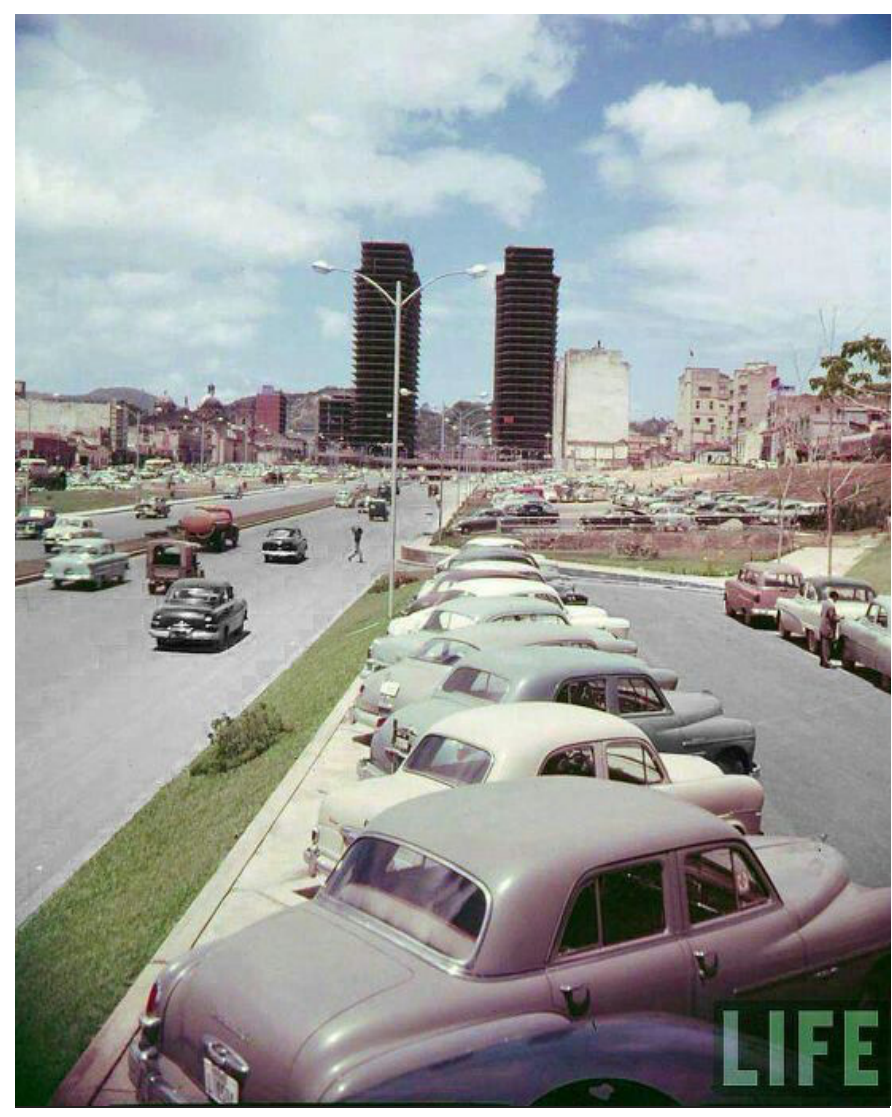

Figura 2: Avenida Bolívar y Centro Simón Bolívar en construcción. Revista Life. Cornell Cappa, 1953.

Nadie puede discutir el valor para un arquitecto conocer una obra de primera mano. Ante el viaje y el primer encuentro con nuestras obras favoritas, o al encontrarnos con obras de admirados maestros, tomamos conciencia de su dimensión, sin el estorbo del saber interior, y así podemos asombrarnos y maravillarnos. Al ver un edificio por primera vez, somos capaces de percibirlo con una exactitud contemplativa, que nos sumerge, nos desborda y nos arrastra a lo estético.

"Si la vida toda es un tránsito, podemos deducir que viajar es la manera más genuina de vivir" (Vegas, 2011). Para muchos arquitectos excepcionales, los viajes son sin duda un mecanismo para incitar la capacidad de observación, y por tanto la capacidad analítica ante la tangibilidad de las obras, como lo muestran los dibujos de los cuadernos de viaje del arquitecto venezolano Martin Vegas Pacheco ${ }^{11}$.

Estas observaciones empíricas revelan una nueva forma de ver que involucra al arquitecto en un doble sistema de observación - uno que trata de descubrir la forma, la constitución y particularidades funcionales del edificio, y otra que la circunscribe su lugar. De esta forma el edificio se ve atravesado por un arquitecto consciente de lo que lee en la forma. La mirada se afirma una relatividad cognitiva, de tal manera que la interpretación de la arquitectura depende también de la mirada del arquitecto, donde participan sus sensaciones, percepciones y experiencias.

A pesar de que las guías de viaje hoy día revisten de cierto prestigio, una limitada atención académica se ha concentrado en la producción, análisis y contenido de las guías de arquitectura, cuya aparición y especificidad es reciente, y difieren de las guías de viaje frecuentemente utilizadas por viajeros. Según lo define Fiona Smith las guías de arquitectura funcionan como "Culture Brokers"12, es decir son mediadores entre el arquitecto, el lugar y la experiencia de recorrer la ciudad en si misma. Claros antecedentes son las guías producidas por Karl Baedecker (Alemania) y John Murray III (Inglaterra) en el siglo XVIII. En Caracas destaca con un formato similar a las guías Baedecker, el libro rojo "Caracas, Guía Histórica artística e indicador general", editado en 1951 por Terzo Tariffi, que posee un carácter turístico, y la austera "Guía de edificaciones contemporáneas en Venezuela" del arquitecto Mariano Goldberg (Caracas,1980) donde se muestran en forma breve plantas, fachadas y sketches para poder explicitar obras contemporáneas relevantes de la capital en los años ochenta.

Pero una guía privilegia contenidos y silencia otros. En este caso, nos propusimos ofrecer una visión totalizadora que nos llevó a abarcar 3 grandes tiempos: pasado, presente y futuro. El primer tiempo, "la Historia de Caracas a través de sus planos" es un relato que reconstruye y reconoce en la ciudad su proceso de crecimiento y urbanización, utilizando la representación como herramienta. Una narración que habla del abandono de la historia, producto de la modernidad súbita, donde se evidencian las operaciones urbanas y arquitectónicas que propiciaron el progresivo alejamiento del damero fundacional, y donde también es posible visualizar las transformaciones tipológicas y urbanas que se han producido desde la edificación de la Catedral de Caracas hasta el presente.

Esta forma de análisis nos proporcionó pistas para poder encontrar una figura a la cual asociar la ciudad ${ }^{13}$. El magnífico plano de Eduardo Rohl, nos muestra la figura de un caballo recostado contra el Ávila ${ }^{14}$, una zona urbanizada que se fue construyendo por paños, y en cuyo corazón se encuentra el damero fundacional. De esta forma también confirmamos que la ciudad tuvo estrategias y reglas de crecimiento, que en muchos casos fueron disímiles, opuestas, y azarosas, asociadas a tramas y lógicas inmobiliarias aisladas que se desarrollaron sin control $^{15}$. Modelos de urbanización con se expandieron conquistando los terrenos al este, ocupando las grandes extensiones de las haciendas entre los cauces de las quebradas, donde identificamos trazados con geometrías irregulares, que no se comunican entre si $^{16}$.

La propia historia urbana expresada en la cartografía nos condujo a dividir la capital en diez zonas, descritas en un segundo tiempo: el presente. En estas zonas con claras características urbanas, geográficas y ambientales cuyas lógicas reflejan la ocupación del valle central y sus valles secundarios, se describe la arquitectura y los espacios públicos estructurantes, construidos entre 1560 y 2012. Se producen así 364 miradas críticas de obras que recogen lo más representativo de la arquitectura colonial, neoclásica, art-deco, internacional, moderna y contemporánea de la ciudad. Cada obra se sitúa en un plano y se muestra a través dibujos arquitectónicos que son complementados con referencias escritas, anécdotas, y descripciones. Logradas fotografías nos muestran múltiples edificaciones, tipologías y envolturas urbanas que nos acompañan, consciente o inconscientemente, en la memoria individual del habitante de la ciudad de Caracas. 


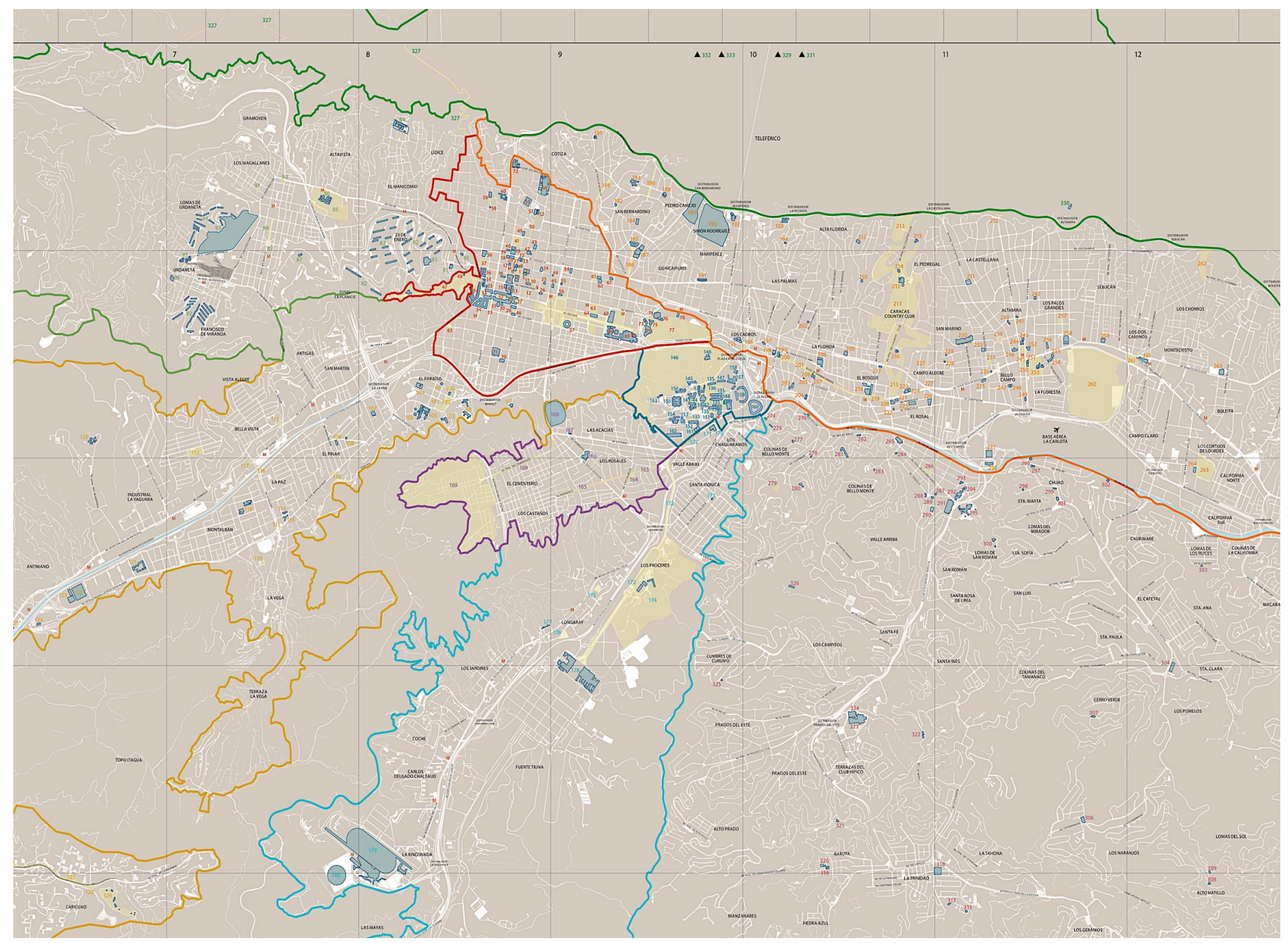

Figura 3: Caracas del valle al mar, guía de arquitectura y paisaje. Plano desplegable que muestra la división de las zonas de la ciudad.

El tercer tiempo, "Caracas a futuro" muestra a través de imágenes de proyectos en desarrollo y opiniones de especialistas, los problemas, amenazas y oportunidades de la capital, debatiendo visiones opuestas de desarrollo a través de grandes proyectos como el concurso "Parque la Carlota, parque verde metropolitano"16 o la autoritaria "Plaza de la Revolución"17. Se abordan temas medulares como la gobernabilidad, la importancia de la capitalidad, la necesidad de canalizar la ciudadanía desde el poder, el respeto al monumento, el rescate de los espacios públicos y la necesidad una arquitectura que realice aportes a la ciudad. Aspectos que en cualquier otra sociedad resultan obvios, pero que en el contexto actual de Caracas son importantes de recordar.

\section{TACTICAS URBANAS PARA CARACAS}

Pero, ¿que tácticas urbanas sugiere la guía?. La primera se deriva de su propio título: "Caracas del valle al mar", donde se persigue afianzar la histórica relación entre Caracas y el litoral considerando al Ávila como un parque interior ${ }^{18}$ El Ávila no es sólo el marco geográfico del Valle de Caracas, es un gran parque nacional compartido por los habitantes del litoral central y de la capital. Caracas como ciudad caribeña, ha estado vinculada al mar, al litoral, y su crecimiento y formación están históricamente soportados en una relación dialéctica que comenzó con el camino de los Españoles del siglo XVI, la ruta del ferrocarril en el siglo XVIII, y se modernizó con la construcción de la autopista y el teleférico en el siglo XX. Hoy esa relación necesita volver a existir con fuerza, y potenciarse con nuevos proyectos.

La segunda consiste en rescatar la memoria urbana y el patrimonio, contrastando imágenes el período de esplendor de la obra con imágenes del estado actual, para señalar de forma crítica su valor en el contexto de la ciudad y poner en evidencia su deterioro con el ánimo de fomentar la corresponsabilidad de su rescate entre los diversos actores encargados de su cuido y preservación. De manera nostálgica, incluir fotografías históricas también aspira mostrar esa voluntad de progreso hoy ausente, como referente para lo que podría volver a ser esta ciudad en el futuro.

La tercera, es la puesta en valor de obras icónicas de la arquitectura que la han materializado como una urbe compleja y heterogénea, así como una valoración del rol del arquitecto y sus aportes al desarrollo de la ciudad; pero también el descubrimiento y visibilidad de obras y arquitectos anónimos que cuyos aportes no son menores en la capital. A su vez, la guía ha despertado iniciativas socio-culturales 

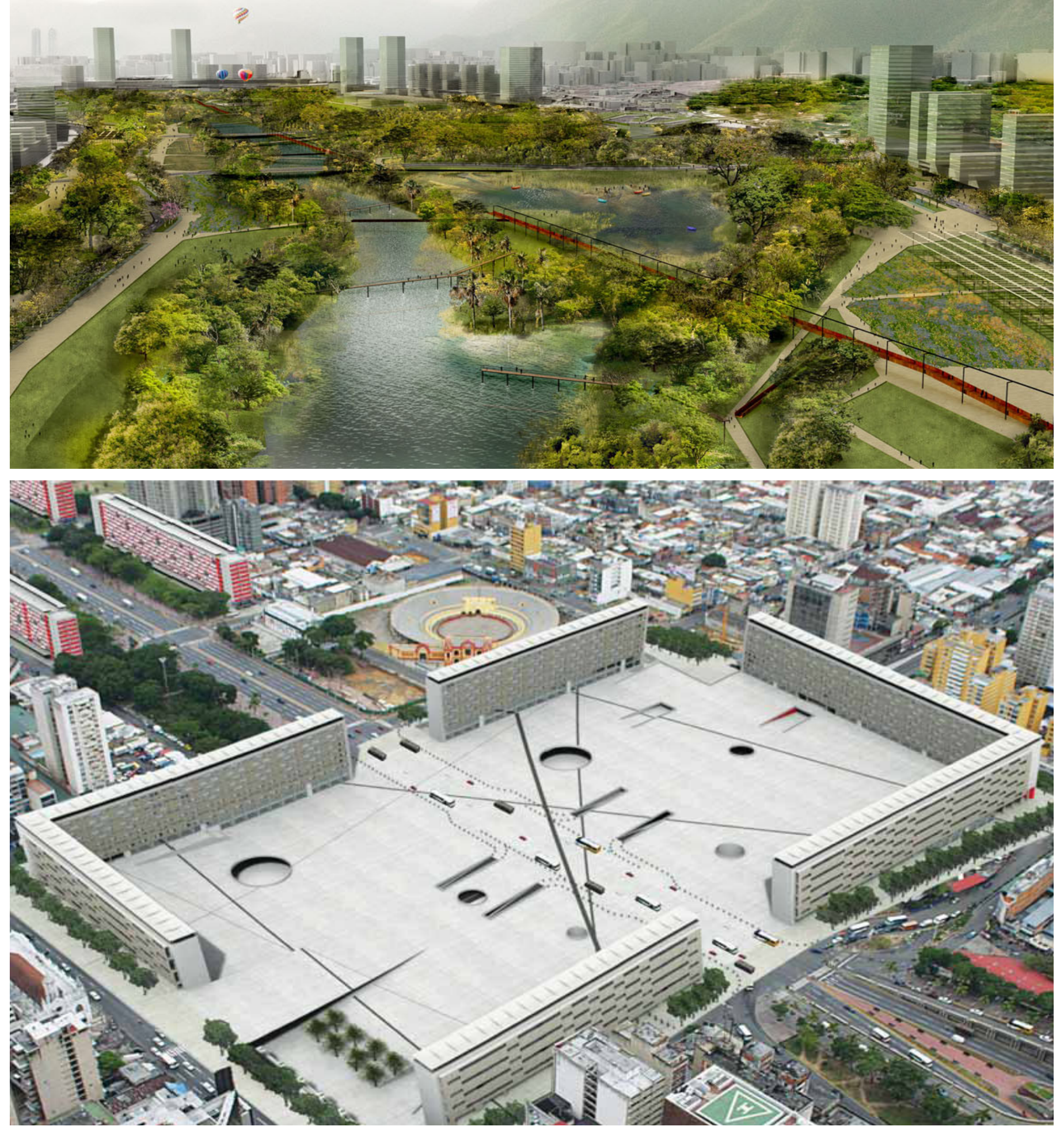

Figura 4: Proyecto ganador concurso Parque Metropolitano La Carlota,

2013. OPUS, Manuel Delgado, Jorge Jaramillo. (arriba) Proyecto Plaza de la

Revolución, 2013. OPPPE. (abajo) 
independientes como "Caracas en 365"19, que persigue estimular al ciudadano a visitar la arquitectura y espacios los emblemáticos de la capital, mediante la organización de recorridos arquitectónicos, peatonales y gratuitos para el acercamiento a las obras, el disfrute lúdico e intercambio colectivo, como una valiente forma de reconquista del espacio público .

Quizás la estrategia más sugerente es la que nos muestra Caracas a futuro, donde la investigación "guía también a la ciudad". Carlos Raúl Villanueva expresaba permanentemente en que "era más importante conocer cómo será el futuro de la sociedad, que el futuro de la ciudad... Esta idea recoge la histórica relación dialéctica entre el espacio y la sociedad que lo produce, considerando que cada sociedad organiza su espacio de acuerdo a su naturaleza y contenido" Por ello pensar en el futuro de Caracas requiere previamente considerar y actuar sobre la conformación de su futuro político, económico y social, donde el pensamiento político del arquitecto es esencial en la conformación de escenarios urbanos prospectivos ${ }^{20}$.

Resulta útil entonces mirar a Caracas a través de una guía, una herramienta que muestra un relato de un proceso, abierto, dinámico, complejo, donde Caracas se dibuja, se redefine y se condensa en una forma de relectura, que valora el pasado, evidencia el presente y delinea su futuro. Con ella se podrán esbozar tácticas urbanas útiles a las transformaciones profundas que ella necesita. Acciones urgentes que transformarían la difícil historia que describe hoy a Caracas, como un territorio de grandes conflictos, y que podría catapultarla a una nueva etapa, más allá de la modernidad.

\section{NOTAS}

1. Fotógrafo nacido en Hungría, hermano de Robert Cappa, que trabajo para la revista LIFE a partir de 1946, y fue miembro de la agencia de fotografía MAGNUN a partir de 1954.

2. Fabry, (Hungría,1926) llega a Venezuela en 1951. En 1953 comienza a trabajar en el Caracas Daily Journal como reportero gráfico con un estilo propio. Sus fotografías figuraron en publicaciones como Time, Life y The New York Times.

3. Gzyl, Stefan. "Prácticas desarticuladas: la percepción de la arquitectura venezolana en el exterior".

4. Gzyl, Stefan. "Prácticas desarticuladas: la percepción de la arquitectura venezolana en el exterior".

5. Clifford Charles Wendehack, Frederick Law Olmsted, John R. Van Kleek, John Eberson, Arthur Froelich, o la oficina de Holabird \& Root \& Burgee, asi como Marcel Brewer, Donald Hatch, Richard Neutra, Gio Ponti, o Roberto Burle Marx fueron algunos de los arquitectos extranjeros contratados para diversos proyectos públicos y privados, que convirtieron a Caracas en el centro de atención de la arquitectura internacional. Localmente Carlos Raúl Villanueva, Carlos Guinand Sandoz, Alejandro Pietri, Cipriano Dominguez, Juan Andres Vegas, Luis Malausenna o Martin Vegas, proyectaron una vigorosa arquitectura atendiendo el llamado de la modernidad.

6. Stefan Gzyl, en su investigación "Prácticas desarticuladas: la percepción de la arquitectura venezolana en el exterior", muestra en este grafico el período donde se produce la mayor difusión de la arquitectura venezolana entre 1950 y 1960. El gráfico fue producido tomando como fuente el Catálogo de la RIBA, que después del Avery de la Universidad de Columbia, tiene una completa colección hemerográfica, tomando como muestra 38 publicaciones internacionales, desde 1945 hasta el 2014. Cada color representa una publicación. Los colores fríos son publicaciones europeas y los cálidos publicaciones americanas. Cada rectángulo representa un artículo sobre arquitectura venezolana. En los casos donde hay varios artículos por año en una publicación dada, los rectángulos se acumulan verticalmente. Gzyl, también investiga otras fuentes; cito: “En el año 2008 la editorial Phaidon publicó este ambicioso volumen, el cual recopilaba lo más notable de la producción arquitectónica mundial del nuevo siglo. El libro incluye más de mil edificaciones en 89 países construidas desde el año 2000 las cuales según se explica, constituyen una muestra de la increíble diversidad y riqueza de la producción arquitectónica contemporánea. Este volumen, además, es una versión actualizada de un primer libro..... publicado en el año 2004 y que se centraba en la última década del siglo XX. En ninguno de los dos libros se menciona a Venezuela."

7. Camacho, Oscar Olinto. Presentación "Caracas del valle al mar, guía de arquitectura y paisaje".

8. Tal y como lo declaraba en periódico Times en 1836 “Mr. Murray has succeeded in identifying his countrymen the world over. Into every nook which an English man can penetrate he carries his Red Handbook. He trusts to his Murray as he would trust to his razor, because it is thoroughly English and reliable".

9. El filosofo francés, Focault, basado en la idea de la observación empírica acuño el termino de "mirada medica" o "medical gaze", que define la práctica de basarse en la observación de los fenómenos físicos para desarrollar principios generales de cómo trabaja el cuerpo humano.

10. Martín Vegas Pacheco, Premio Nacional de Arquitectura de Venzuela, 1998.

11. Jezewski (in Jezewski \& Sotnik, 2001) definen "culture broking" como "El acto de tender un puente, que une o mediar entre los grupos o personas de diferentes orígenes culturales con el fin de reducir los conflictos o la producción de cambio".

12. Un problema histórico, que muchos expertos han llegado a visualizar solo a través de herramientas contemporáneas como el "Google Earth" o el uso de modernos "drones".

13. Vegas, Federico. "Una ciudad en sus redes y en sus tramas". Pág. 14.

14. Tal y como se muestra en el plano de 1941, donde pudimos extraer los trazados de los principales urbanismos que se construyeron entre 1917 y 1948.

15. En el ensayo "Caracas una ciudad en su redes y en sus tramas", (Vegas,González: 2000) desarrollan esta idea de la ocupación del valle por paños.

16. El concurso para el nuevo Parque Metropolitano La Carlota en Caracas tiene el propósito de transformar el aeropuerto de La Carlota en un parque verde metropolitano, una pieza fundamental del sistema de espacios públicos de la ciudad. El proyecto ganador del concurso, fué la propuesta de OPUS con Manuel Delgado y Jorge Pérez Jaramillo.

17. La "Gran Plaza de la Revolución” proyectado en el corazón de la Avenida Bolivar, es desarrollado y promovido por la Oficina Presidencial de Planes y Proyectos Especiales, adscrita a la Presidencia de la República de Venezuela.

18. William Niño sostiene "La hipótesis que fundamenta el mapa de la Ciudad Ideal del 2030 define a Caracas como un aro perimetral de funcionamiento que envuelve la montaña; este paisaje se extiende desde Catia hasta Petare y desde allí, hasta Guarenas-Guatire: Hacia el norte el frente marítimo se despliega desde el Puerto de La Guaira y el aeropuerto de Maiquetía, hasta el extremo de Los Caracas; una "carretera del placer" vincularía a Guarenas con la Ciudad Vacacional Los Caracas; una Autopista del trabajo relaciona Catia con Maiquetía; en el centro vibra el jardín más gigantesco del mundo: el Ávila, la selva húmeda tropical".

19. Caracas en 365 , es una iniciativa independiente del comunicador social Luis Bergolla y la arquitecto Mitchelle Vidal promovida a través de la red social Instragram bajo el nombre CCSen365.

20. Camacho, Oscar. (2016) En http://entrerayas.com/2016/02/ presentacion-de-la-guia-de-arquitectura-caracas-del-valle-al-mar/ 